\title{
Putting Theory into Practice: Designing a Curriculum According to Self-determination Theory
}

\author{
Rebecca Huxley-Binns and Graham Ferris \\ Nottingham Law School, Nottingham Trent University U.K.
}

\begin{abstract}
Building on existing research into the affective domain in legal education, volition and selfdetermination theory (SDT), we explain how to categorise student motivation types and design a curriculum which meets and supports, or at least does not undermine or damage, students' intrinsic or extrinsic motivations. This categorisation process allows the curriculum designer to obtain a fresh insight into student engagement, particularly by appreciating how to enhance the active forms of extrinsic student motivation, which leads students to internalize their goals, take over the responsibility for their learning and develop a strong sense of value for their choices. That insight, coupled with an appreciation of SDT's identification of the three human motivational needs (autonomy, competence and relatedness), allows the curriculum designer consciously to address learning, teaching and assessment at a macro-and micro-design level. As one method of approaching curriculum design, we show how to change the learning culture; the environment enables a stronger understanding of students' behaviours, volition and motivation, creating new ways for the students to internalise their extrinsic motivation (own their learning), leading to fully self-determined actions.
\end{abstract}

\section{Keywords: Student Engagement, Self-determination Theory, Motivation, Intrinsic Motivation, Extrinsic Motivation, Curriculum Design}

\section{Introduction}

Jurisprudence is the study of legal philosophy. Jurisprudence was always offered as an option module on the final year of the LLB Law programme at Nottingham Law School, United Kingdom, but for at least 15 years prior to 2010, it did not attract sufficient student numbers to run. It was impossible to tell with certainty why students did not opt for the module as mechanisms were not and are not in place to assess why students elect not to exercise choice in a particular way, but experience tells us that jurisprudence is traditionally viewed by all students as intellectually demanding, abstract and obtuse, inaccessible and irrelevant to legal professional practice (Barnett 1995). ${ }^{1}$ There was, nevertheless, great staff enthusiasm to design and deliver a jurisprudence module. The tutors acknowledge it $i$ intellectually demanding, but it deals with real problems, offering realistic possible solutions, embedding conflicting but valid values and value systems, within a broad legal social context.

Early module design meetings coincided with ongoing research into the affective domain in legal education (Ferris and Huxley-Binns 2010a, Ferris and Huxley-Binns 2010b, Ferris and Huxley-Binns 2011), so it was logical to adopt the insights gained in our research on volition (Frankfurt 2006) and self-determination theory (Deci 1971, Kruglanski et al 1971, Lepper and Greene 1975) when developing ideas for the new module. A lucky online find of Michael Sandel's 'Justice' videos ${ }^{2}$ allowed us to supplement our design ideas with multi-media to support student engagement.

\footnotetext{
${ }^{1}$ Student conservatism around option choice seems to be common across subject areas (Brennan et al 2010)

${ }^{2}$ www.justiceharvard.org
} 
This paper explains the theories and models above, illustrates how we have implemented the elements of the theories into the design of the curriculum of a new jurisprudence module, now called Critical Legal Thinking (CLT), for first delivery in 2010-2011. The module attracted 110 students from a cohort of 250 students, and has recruited similar numbers on an annual basis since. We offer an evaluation of the success of the endeavour to date.

\section{Volition}

Given that law students have chosen to study law, there must be some factor which has caused them to value or care about learning law. Biggs (2003) has written extensively on taking account of the interaction between learner activities, the teacher activities and alignment of the curriculum in light of the learning climate and student motivation. He asks, "How can we enhance the value of the task to the student? The general answer is clear enough: make their work important to them." (Biggs 2003, 60) If student motivation is captured by doing what they perceive as being important, then it becomes salient to consider what is important to law students. A fertile approach is to start by acknowledging that what is important is that which we care about. As the philosopher Frankfurt (2006) has pointed out, we should take that which we care about very seriously. The human abilities to reason and love "play critical roles in determining what we think and how we are moved to conduct ourselves" (2006, 1 emphasis added). In essence, Frankfurt reveals that caring and reasoning about what we care about form our volition, which in turn affects the freedom of our will and thus our motivation $3 .{ }^{3}$ If volition gets us started, motivation keeps us going. It is logical therefore to suppose that law students have volition to study law because they are studying law. Jurisprudence offers students a space in which to debate ethics and morality in a legal context, so what we had to address was how to capture existing student volition and ensure we then kept students motivated during the module.

\section{Self-determination theory}

Self-determination theory (SDT) is a macro-theory of human motivation. Early studies in the field now known globally as SDT discovered that performance in an activity which is intrinsically motivated could be negatively affected by applying an external motivating feature such as a reward or deadline. On the other hand, agent choice or positive feedback could enhance intrinsic motivation and the feeling of self-determination. Take a reasonably straightforward example: A talented, amateur tennis player dedicates a significant amount of her spare time to playing tennis. She enjoys herself. She describes her dedication to her hobby as being for the 'love of it'. SDT describes her motivation as intrinsic. Early SDT studies posited that offering the tennis player a prize for every good serve, or brilliant back hand she played, could negatively impact on her motivation to practise. Rewarding a person for doing what they would do voluntarily and happily anyway could undermine or damage that person's intrinsic motivation. Deci (1971) ascribed the negative effects of reward to a 'shift in the perceived locus of causality.' In other words, our motivation to do something which we do for ourselves can be damaged if we think that the reason to do it comes from an external force. More simply, if we believe our reason to act, or our purpose behind our motivation is not our own, we tend to be less motivated. Further SDT studies revealed that external factors including threats (Deci and Cascio 1972), deadlines (Amabile, DeJong, and Lepper 1976), directives (Koestner et al 1984), and competition pressure (Reeve and Deci 1996) also undermined intrinsic motivation whilst, conversely, choice and the opportunity for self-direction (e.g., Zuckerman et al 1978) enhanced intrinsic motivation.

We knew that the jurisprudence module at Nottingham Law School would be offered as an optional final year module because that was a decision made by the programme designers. We also knew that for our potential students to elect to take our module would involve making an active choice to study jurisprudence rather than a dissertation module with a title of the student's own devising. Given this environment of choice, SDT research was significant in the design of our new module, because our tasks were to encourage students to choose the option and then design the learning experience to facilitate the cohort to become (more) motivated by their studies.

\footnotetext{
${ }^{3}$ Frankfurt's wholeheartedness, when what we want to do and what we are engaged in are aligned, seems to share features of 'flow', Csikszentmihalyi (1990)
} 
The first decision the module leadership took was to devise a new module title. We wanted to find a title which attracted choice (volition) and which sounded like something students would not see as portentous and didactic, as 'Jurisprudence' or 'Legal Theory' might. We wanted a title that resonated with capacities students felt they already had; drawing attention to processes, not transmission; and to competence, not ignorance. The first two years of undergraduate study would have included tuition about 'thinking critically' about the law, so the module became Critical Legal Thinking. This decision was both instinctive and also well-founded in the research; one of the human needs identified by SDT (below) is competence and a person feels competent when they feel capable or efficient or effective (Elliott, McGregor and Thrash 2002). Labelling the module by a title that refers to capacities and skills that the students feel they already have enhances their feelings of competence and their self-esteem.

Next we had to consider what might motivate an election for CLT so that students would choose it. Effectively, this committed us to an exploration of how to design a curriculum to maintain, support or enhance motivation. This required a careful analysis of types of motivation.

\section{Categories of motivation}

"People have not only different amounts, but also different kinds of motivation. That is, they vary not only in level of motivation (i.e., how much motivation), but also in the orientation of that motivation (i.e., what type of motivation). Orientation of motivation concerns the underlying attitudes and goals that give rise to action - that is, it concerns the why of actions." (Ryan and Deci 2000, 54) SDT claims it is the reasons why people feel they are doing things that are crucial. People engage in what they feel is their own concern. Early SDT (Ryan and Deci 2000, 56) simply distinguished intrinsic from extrinsic motivation:

"Intrinsic motivation is defined as the doing of an activity for its inherent satisfactions rather than for some separable consequence. When intrinsically motivated a person is moved to act for the fun or challenge entailed rather than because of external prods, pressures, or rewards."

More recent SDT (Ryan and Deci 2000) classifies different types of extrinsic motivation and it is highly pertinent to law students, as we shall explore below.

For a few students, the whole programme of legal study is a purely intrinsically motivated activity. It is done for self-interest alone. The student engages with the activity and the activity engages the student. Intrinsic motivation is usually measured by self-report (Deci et al 1994), but there is also a free-choice measurement (Ryan and Deci 2000). For example, if a tutor was working with a student on a one-to-one supervision, and the task was focused on the analysis of a passage in a case or a textbook, and after the completion of the task, the tutor left the student alone for a few minutes, an intrinsically motivated student would continue with the task of their own free choice. Other examples in a law school of activities which are done by intrinsically motivated students might include extra-curricular activities such as moots or debates.

Teachers (just as parents) cannot cause a student (or child) to be intrinsically motivated.

Such a statement is a contradiction in terms. However, teachers and parents can certainly provide a setting which supports an already intrinsically motivated student. Conversely, without care, a parent, teacher or curriculum designer can undermine intrinsic motivation. A sub-theory of SDT is Cognitive Evaluation Theory (CET) and was presented in Deci and Ryan (1985). CET suggests that facilitation of intrinsic motivation is dependent on there being feelings of competence in the actor along with a sense of autonomy. These are two of the three basic human needs identified by SDT, and which we explore in detail below.

For the few undergraduate law students who are truly intrinsically motivated, those students' volition is self-perpetuating provided we enhance and do not undermine that motivation. In an SDT self-report, the student might say that they chose to study law because it is fascinating, because it permeates all of life and it is enjoyable simply to learn how it works. However, the authors assert here that the majority of law undergraduates are not intrinsically motivated by the study of law and therefore the principles of CET do not apply to most of our students. 
Undergraduate law students are, on the whole, extrinsically motivated. Although a student might happen to enjoy the process of study, if he ${ }^{4}$ is studying in order to become a solicitor, he or she is extrinsically motivated. So too is a student who regards the law degree as a necessary evil on the path to her fulfilling judicial career. They regard the law degree as a means to an end. All ends are extrinsic perceived loci of causality.
"Extrinsic motivation ... requires an instrumentality between the activity and some separable consequences such as tangible or verbal rewards, so satisfaction comes not from the activity itself but rather from the extrinsic consequences to which the activity leads."(Gagné and Deci 2005, 331 emphasis added)

The existence of extrinsically motivated students should not (perhaps contrary to most academic's instinct) cause despair. On the contrary, extrinsic motivations are valuable if embraced and facilitated by the tutor. Extrinsic motivation is a form of motivation that, if well supported, allows the student to become more and increasingly self-determined. The key to embracing extrinsic motivations is to facilitate the internalizing of the extrinsic purposes:
"Students can perform extrinsically motivated actions with resentment, resistance, and disinterest or, alternatively, with an attitude of willingness that reflects an inner acceptance of the value or utility of a task ... Frankly speaking, because many of the tasks that educators want their students to perform are not inherently interesting or enjoyable, knowing how to promote more active and volitional (versus passive and controlling) forms of extrinsic motivation becomes an essential strategy for successful teaching." (Ryan and Deci 2000, 55 emphasis added)

Extrinsic motivation is more complex than simply identifying an external causal force. A second sub-theory of SDT is Organismic Integration Theory (OIT) which details the different forms of extrinsic motivation. It distinguishes the more autonomous forms of extrinsic motivation, which have an internal or more internal cause, from the least or lesser autonomous forms of extrinsic motivation, which have an external or controlling cause. A taxonomy of human motivation (adapted from Ryan and Deci 2000 and Vallerand, Pelletier and Koestner $2008,61)$ is provided to assist:

\section{Table 1: A taxonomy of human motivation}

\begin{tabular}{|l|l|l|l|l|l|l|}
\hline & Amotivation & $\begin{array}{l}\text { Extrinsic } \\
\text { Motivation }\end{array}$ & $\begin{array}{l}\text { Extrinsic } \\
\text { Motivation }\end{array}$ & $\begin{array}{l}\text { Extrinsic } \\
\text { Motivation }\end{array}$ & $\begin{array}{l}\text { Extrinsic } \\
\text { Motivation }\end{array}$ & $\begin{array}{l}\text { Intrinsic } \\
\text { Motivation }\end{array}$ \\
\hline $\begin{array}{l}\text { Regulatory } \\
\text { Styles }\end{array}$ & Nonregulation & $\begin{array}{l}\text { External } \\
\text { regulation }\end{array}$ & $\begin{array}{l}\text { Introjected } \\
\text { regulation }\end{array}$ & $\begin{array}{l}\text { Identified } \\
\text { regulation }\end{array}$ & $\begin{array}{l}\text { Integrated } \\
\text { regulation }\end{array}$ & $\begin{array}{l}\text { Intrinsic } \\
\text { regulation }\end{array}$ \\
\hline $\begin{array}{l}\text { Associated } \\
\text { Processes }\end{array}$ & $\begin{array}{l}\text { Perceived } \\
\text { noncontingency. } \\
\text { Low } \\
\text { perceived } \\
\text { competence. } \\
\text { Non } \\
\text { relevance. } \\
\text { Non } \\
\text { intentionality. }\end{array}$ & $\begin{array}{l}\text { Saliance of } \\
\text { extrinsic } \\
\text { rewards or } \\
\text { punishments. } \\
\text { Compliance/ } \\
\text { reactance. }\end{array}$ & $\begin{array}{l}\text { Ego } \\
\text { involvement. } \\
\text { Focus on } \\
\text { approval } \\
\text { from self or } \\
\text { others. }\end{array}$ & $\begin{array}{l}\text { Conscious } \\
\text { valuing of } \\
\text { activity. } \\
\text { Selfendorsement } \\
\text { of goals. }\end{array}$ & $\begin{array}{l}\text { Hierarchical } \\
\text { synthesis of } \\
\text { goals. } \\
\text { Congruence. }\end{array}$ & $\begin{array}{l}\text { Interest/ } \\
\text { enjoyment. } \\
\text { Inherent } \\
\text { satisfaction. }\end{array}$ \\
\hline $\begin{array}{l}\text { Perceived } \\
\text { Locus of }\end{array}$ & $\begin{array}{l}\text { Impersonal } \\
\text { causality }\end{array}$ & External & $\begin{array}{l}\text { Somewhat } \\
\text { external }\end{array}$ & $\begin{array}{l}\text { Somewhat } \\
\text { internal }\end{array}$ & Internal & \\
\hline
\end{tabular}

To summarise, we assert that most undergraduate law students have an extrinsic locus of causality in respect of their studies, but we want them to choose and be able fully to be engaged in our module whilst under our tutorage. OIT tells us that internalization of the perceived locus of causality is itself an active transformation to assimilate an externally regulated motive into an integrated regulation. Internalization of an extrinsically motivated activity can allow a student to be moved along a continuum to a more interesting and engaging learning experience. The

\footnotetext{
${ }^{4}$ As is common practice in the law, we use the male term to include the female, and more unusually, we will sometimes use the female to include the male. This is to avoid the clumsy use of 'he or she', or even 's/he'
} 
phenomenon of internalizing is not unique to self-determination in the educational field: it is a social practice, it can be observed in children and adults as we develop and integrate values into our lives. Self-determination theory does not require us to do anything in our teaching that we do not already do in our lives; we may speak of adopting a value, or a position, or maturing in our opinions, but we might otherwise speak of internalizing an extrinsic locus of causality, or even of owning our decisions or opinions. The key is internalizing.

Before we address how we designed the CLT curriculum to facilitate internalization, it may be valuable to articulate the key descriptors used in the table above so the categories are better understood, as is movement across them. From amotivation on the left to intrinsic motivation the right, there are six categories.

1. Amotivation: This student has no motivation at all ("there is no point", "I cannot do it", "I do not care"). There is very little teachers can do with an amotivated student unless the student responds positively to the inculcation of the three human needs in the curriculum (below) and moves across the continuum of the taxonomy towards an extrinsically motivated situation. At the very least this requires the student to attend classes to discover the nature of the curriculum, and an amotivated student does not necessarily even turn up to classes. He is alienated and at risk of dropping out. However, we suggest that some students are sometimes wrongly classified by some tutors as being amotivated when they are, in fact, extrinsically motivated and externally regulated.

2. External regulation: This category of motivation describes the least autonomous of the extrinsic motivation types. A student in this category does have some motivation, but the cause of the motivation is wholly external, for example, to comply with a parental mandate ("I wanted to take English Literature but my parents told me I had to take law because it is more practical"5) or to achieve the certificate for passing the qualification. These students are usually easy to spot during an exercise in class - they are the ones who start to work only as we approach. There is no genuine self-motivation at all.

3. Introjected regulation: A student who has an introjected form of extrinsic motivation is either stirred on by an externally imposed guilt-trip or by fear that he will have low self-esteem if he does not complete the activity ("I wanted to prove to myself/others that I could do it!"). However, his motives are partially internalized because he feels the task reflects on his self-worth; it is something he should want to do, rather than a pointless but necessary task performed to satisfy the demands of others. The activity is not truly self-determined because there is no assimilation of the goals.

4. Identified regulation: The 'identification' part of the motivation is where the student recognises the study is a means to an end and willingly undertakes the activity to achieve the end ("I wanted to fight for the underdog! I have to be a solicitor to do that!"). Undergraduate law students commonly see the LLB as a stepping stone either to the professional programmes or to a non-legal professional career. Such students are extrinsically motivated. However, they have applied some reason and reflection to their actions and have recognised that there is some value from which they will benefit ("I had to do something to enhance my career prospects"). This is what is meant by 'somewhat internal' in the taxonomy above. As teachers, this is an area where we can hope to be very effective (Byman and Kansanen 2008, Brophy 1999, 2004, Vansteenkiste, Lens and Deci 2006, Fives and Alexander 2001) because we can explain the purpose of the activity to assist the student to identify their internal cause of their extrinsic motivation.

However, a word of warning to avoid disappointment:

\footnotetext{
${ }^{5}$ Many of the exemplar quotations provided in this paper are direct quotations from Twitter users, reproduced (as promised) anonymously here; sincere thanks to all who responded to our tweets
} 


\begin{abstract}
"It is important to note that the SDT model of internalization is not a stage theory and does not suggest that people must invariantly move through these 'stages' with respect to particular behaviors. Rather, the theory describes these types of regulation in order to index the extent to which people have integrated the regulation of a behavior or class of behaviors. As such, SDT proposes that, under optimal conditions, people can, at any time, fully integrate a new regulation, or can integrate an existing regulation that had been only partially internalized." (Gagné and Deci 2005, 335)
\end{abstract}

5. Integrated regulation: A student who has integrated the activity also regards the activity of study as a means to an end, and the means as distinct from the end, but there is congruence between the means and the end ("I want to represent victims of human rights abuses. I have to become a barrister"). The more a student assimilates the reason for the activity to herself, the more self-determined she is, even if her motivation has an external locus of causality. "With integrated regulation, people have a full sense that the behavior is an integral part of who they are, that it emanates from their sense of self and is thus self-determined ..." (Gagné and Deci $2005,335)$. Thus, she learns to write clearly because clarity of expression is important to her; it enables her to reason well, and be persuasive, which in turn she will need at the Bar. Being able to think and communicate clearly becomes an aspect of her identity.

6. Intrinsic: The intrinsically motivated student, who finds learning a joy and who is a joy to teach, has been described above.

We suggest that there may be little outwardly to distinguish an integrated extrinsically motivated student (category 5 above) from an intrinsically motivated student (6); only self-reporting with a careful analysis of the report by an SDT expert would tell them apart, so our focus has been somewhere in the middle of the taxonomy. Through the design and delivery of the curriculum, we have attempted to enhance the active forms of extrinsic motivation leading students "to internalize the responsibility and sense of value for extrinsic goals" ... to foster "the internalizing and integration of values and behavioural regulations" (Ryan and Deci 2000, 56). The point is worthy of repetition: we cannot force a person to become intrinsically motivated. However, as we seek to show here, we can establish a curriculum framework which allows the student the fullest opportunity to internalize and integrate the perceived locus of causality of their extrinsic motivation. How? The answer is in OIT. Internalizing and integrating requires acknowledging, addressing, and supporting the three human needs. These are innate needs of each human being; they are autonomy, competence and relatedness. We have interpreted these broadly to mean we should design the curriculum to allow the students to make choices (enhancing autonomy), to make valuable and valued contributions based on instinct and prior knowledge to explore novel concepts and ideas (enhancing competence) within a supportive group (enhancing relatedness). We detail these human needs in detail below.

In summary, where the perceived locus of causality is intrinsic, CET indicates that enhancing motivation is achieved by supporting autonomy and competence. Where the perceived locus of causality is extrinsic, OIT reveals that internalization and integration are facilitated by supporting autonomy and competence, and also by paying attention to the need for relatedness. We realised that we could design a module that met the three SDT needs of the students, then they would be far more likely to adopt or internalize the elements of study. If the students felt that the work was their own (i.e. done for reasons they personally endorsed) then they would have a stronger and more sustainable motivational state and would feel better in themselves. If the student felt that the ends were fulfilling their basic needs then they would be more likely more fully to internalise them, but if they felt the ends were not fulfilling, they could feel used and the ends would be likely to remain externalised. We assert the latter is an accurate description of an assessment-driven model of curriculum design.

\title{
Autonomy
}

Autonomy does not involve unfettered freedom. For example, we cannot design a curriculum to give a student a choice not to take an assessment. Rather, autonomy in the educational SDT context describes particular attitudes on the tutor's part. Reeve (2002) describes tutors who 
support the autonomy of the students as being responsive (e.g. spending time listening), supportive (e.g. praising the quality of performance), flexible (e.g. giving students time to work in their own way) and able to motivate through interest (e.g. supporting intrinsic motivation) (Byman and Kansanen 2008, 613). Fives and Alexander $(2001,246)$ have stated that "the teacher must pose stimulating questions, guide students through open discussion and seek confirming evidence from students for their ideas". In the Critical Legal Thinking tutorials, we pose questions that have no 'right' answer, for example:

- List what you consider to be human virtues. How would you prioritise them?

- Robin Hood stole from the rich to give to the poor. Is this "justice"?

- If a defendant is on trial on indictment, and he is a black man, should there be a racial mix on the jury?

- Is there one right answer to every question we can ask, even if we don't know what the answer is?

- It is natural for human beings to reproduce, so is contraception a violation of natural law?

Autonomy is facilitated by the module tutors allowing the tutorial discussions to go in the direction the students want, with a light hand on the tiller, and with very broad mandates in terms of syllabus coverage. We do, eventually, ask a student to apply a theory to an example, or to ground an opinion in a theory we have already discussed, simply to show the student how to found an opinion in a theory or vice versa, and this is good practice and constructive alignment of the teaching, learning and assessment, but in the first few tutorials at least, the students steer the discussion.

The assessment on the module is a written project of up to 6,000 words. In order more fully to support student autonomy, we created the opportunity for students to negotiate the title of the project. We do not force students to create their own title, because that might undermine confidence, damage competence and contradict autonomy. We offer 'set' project titles, and students can elect either one of those, but we also allow students who wish to create their own title subject to module leadership approval. The only mandates for all titles are that the students have to argue for or against their proposition; and the discussion has to include an analysis of at least two of the theorists studied on the module. We have to date always approved the subject matter/essence of the title, even if we invariably suggest tighter wording to narrow the focus of the project to something manageable within the word limit. In 2010-2011, of the 109 students on the module, 19 students chose their own title, although two later reverted to one of the set questions, and those two students reported that they felt uncomfortable and anxious that they might be heading into unknown territory without help (we will investigate the human need for competence below).

Autonomy is not restricted to student choice. The three academics who designed the module were already teaching across different modules and different programmes. We could not realistically find the time to take on the delivery of a new module in its entirety and from scratch. However, sufficient 'buzz' had been generated from the initial discussions that we were able to fill the lecture slots with one different academic each week for the whole module. Although academics have autonomy in choice of content of a Jurisprudence module (Seow Hon Tan 2009), the syllabus we have adopted happens to be quite traditional (Barnett 1995), including law and morality (Bentham, Mill, Aquinas, Finnis, Hart, Devlin, Dworkin, Fuller), law and justice (Aristotle, Rawls, Sen and Sandel) and the nature of law and the judicial role (Llewelyn and Frank). We created the broad structure of topic areas that we would like to have covered and emailed all law academics to request volunteers to cover one lecture only. Staff quickly came forward; on the understanding all they would have to do was prepare one lecture, accompanying handout or PowerPoint slides and chat with the module leaders about focus/direction in advance so we could create a tutorial to support the content of the lecture. This autonomy-driven system produced a full team of willing volunteers, many of whom reported that they were delighted to be able to offer a lecture on X (Mill, Bentham, Finnis...) of whom they had not thought for years, but who they loved learning about as, say, an undergraduate. The lecture team was populated with intrinsically motivated staff. The end of module questionnaires revealed that $81 \%$ of students enjoyed or were of a neutral opinion in respect of having different lecturers. Although delighted with the positive feedback, $19 \%$ of students did not like the multiple lecturer model. So 
in order to help students access the various theories, and minimise negative feelings about variety in lecturers, in 2011-12 we adopted explicit themes; in the first term, students studied 'What's the right thing to do' (a blatant adoption of the Sandel model, below) and in the second term 'Where is the law from'?

\section{Competence}

As we have seen, intrinsic motivation and the internalization of extrinsic motivation are enhanced by feelings of competence. It was a challenge to design a module which is perceived to be intellectually difficult and which is in fact intellectually very demanding in such a way that students would feel competent in each class, but also feel able to rise to the undoubted challenge of the material. After extensive discussions about module content, we tackled this element of SDT's human needs in several ways simultaneously.

First, we started the opening lecture with a very simple question; if there are three children and one flute, which of the three children - Anne, Bob or Carla - gets the flute? If unfamiliar with Amartya Sen's hypothesis (Sen 2009, 12), you might wish to decide what you would do. Please do use your instinct and if you are not able (yet or at all) to give a reason for your decision, none is required. This is exactly what we tell our students too.

"Anne claims the flute on the ground that she is the only one of the three who knows how to play it (the others do not deny this), and that it would be quite unjust to deny the flute to the only one who can actually play it ... Bob ... speaks up, and defends his case for having the flute by pointing out that he is the only one among the three who is so poor that he has no toys of his own. The flute would give him something to play with (the other two concede that they are richer and well supplied with engaging amenities). Carla ... speaks up and points out that she has been working diligently for many months to make the flute with her own labour (the others confirm this), and just when she had finished her work, 'just then', she complains, 'these expropriators came along to try to grab the flute away from me'."

We present the case for each child, and then ask the students to discuss the situation among themselves and decide, on a show of hands, who gets the flute. After the votes are cast and some justification for opinions offered by the more confident students in the lecture theatre, the lecturers explain that there is no 'right' answer:

"Theorists of different persuasions ... May each take the view that there is one straightforward just resolution that is easily detected, but they would each argue for totally different resolutions as being obviously right." (Sen 2009, 13)

We use this exercise to introduce some of the module's philosophical theories and concepts; we explain, simply and briefly, that one view would be that of an Aristotelian (for some of those who voted for Anne), a libertarian (some who voted for Carla), and a utilitarian (some who voted for Anne, Bob or Carla, depending on why they voted as they did). The concurrent but conflicting 'rightness' of the opinions of the audience members provides an introduction to pluralism.

In the next lecture we tell the students of one aspect of the 1987 tragedy of the sinking of The Herald of Free Enterprise. After leaving the port of Zeebrugge with its bow doors open, the ferry sank and 197 people died. At the coroner's inquest a man, X, testified that he had been on the ferry and he and dozens of other people had been near the foot of a rope ladder leading to a life boat. A young man, Y, who was petrified by cold or fear was on the ladder and, for at least ten minutes he was unable to move up or down. Eventually X instructed those nearest to push $Y$ off the ladder, which they did, and $\mathrm{Y}$ was never seen again. The others were then able to climb up the ladder to safety. All of the students on the CLT module were taught about this event in their second year criminal law studies to illustrate the possible, if dubious, existence of a defence of necessity to criminal liability. In CLT, the same example is used to distinguish Benthamite utilitarianism from aspects of libertarianism based on self-ownership. We discuss means and ends, and ask whether the ends can justify the means or whether people are and should be ends in themselves. As the module unfolds, we deliberately build on the student's existing knowledge by asking new questions about known events. Cotterrell (2000) has asked "What does jurisprudence 
add up to? For students this is often the hardest question ... For the weakest students, the subject may be incomprehensible because its purpose is not understood. For more able ones, the subject is disturbing because it is seen to disrupt the certainties that much legal education otherwise fosters and relies on". Because we are able to facilitate the development of the students' understanding of philosophical theories in an environment where answers based on existing knowledge and on instinct are acceptable and welcomed, and because of our practical application of SDT, we have created an environment in which students have reported themselves to be happy to be challenged.

In each tutorial, we also make a conscious effort to provide regular and positive feedback. Byman and Kansanen $(2008,608)$ showed that negative feedback fosters perceived incompetence and tends to undermine intrinsic motivation. Negative feedback has also been shown to prevent internalizing extrinsic motivation which prevents integration of the activity into the self:

“Adopting as one's own an extrinsic goal requires that one feel efficacious with respect to it. Students will more likely adopt and internalize a goal if they understand it and have the relevant skills to succeed at it. Thus, we theorize that supports for competence (e.g., offering optimal challenges and effectance-relevant feedback) facilitate internalization". (Ryan and Deci 2000, 64)

We make full use of our perceptions of student behavioural norms to spread feelings of competence. Many students are comfortable, at least, and most are confident with online sources of information. Although the provenance of the source may be of direct and immediate concern to the tutors, the student body, as a whole, cares more for the content than the quality per se. We were able, by a lucky click on a routine internet search, to discover a source that has both excellent content and unimpeachable provenance; www.justiceharvard.org. This is the website of Professor Michael Sandel's "Justice" course at Harvard University, made freely available online. We sought and received his permission to build the first term of lectures and tutorials loosely around aspects of his programme and this provided us with a new way for students to prepare for tutorials. For example, in the first tutorial which is an introductory discussion about utilitarianism, as well as recommending the students to read a short extract from Bentham's utilitarianism, we direct the students to watch Sandel's first episode online and prepare answers to the questions he poses on his website. The episode contains some classic moral conundrums, from the infamous case of $R v$ Dudley and Stephens (1884-85) L.R. 14 Q.B.D 273 (English students take a rather bizarre pride in a well-known English murder being so high profile in an American professor's lecture, but in SDT terms, this embraces the students' feelings of relatedness, below) to the driver of the out of control trolley car, if it goes straight on it kills five, but if the driver turns the wheel, it kills one. Students are commonly familiar with a form of the latter hypothetical ethical dilemma.

In the end of module questionnaire in 2010-2011, completed by the 72 students (from a cohort of 110) present in the lecture, $79 \%$ of students reported that CLT was hard or too hard. This was initially a concern, however, $89 \%$ of respondents reported that CLT was interesting. We subjected the questionnaires to careful analysis and discovered that $55 \%$ of students found CLT to be both too hard and nevertheless it was interesting. From this finding, we conclude that we have established feelings of competence in the student body despite the fact that more than half of the students admitted to being outside their comfort zone. More than half were enjoying themselves whilst they worked hard. In terms of the small group learning in particular, $82 \%$ of students found the tutorials helped understanding, and $86 \%$ that the lectures and tutorials fitted well together.

\section{Relatedness}

The third human need identified by self-determination theory is relatedness. Relatedness has been described by Byman and Kansanen $(2008,608)$ as, "a context where the atmosphere is warm and caring". More specifically in the educational context:

"Because extrinsically motivated behaviors are not inherently interesting and thus must initially be externally prompted, the primary reason people are likely to be willing to do the behaviors is that they are valued by significant others to whom they feel (or would like to feel) connected, 
whether that be a family, a peer group, or a society. This suggests that the groundwork for facilitating internalization is providing a sense of belongingness and connectedness to the persons, group, or culture disseminating a goal, or what in SDT we call a sense of relatedness. In classrooms this means that students' feeling respected and cared for by the teacher is essential for their willingness to accept the proffered classroom values." (Ryan and Deci 2000, 64)

Supporting and enhancing intrinsic motivation is not dependent on relatedness (Cognitive Evaluation Theory, above), but the internalizing and integration of extrinsic motivations are, as revealed by Organismic Integration Theory, above. Despite the vital part that relatedness plays in OIT and SDT, Vallerand, Pelletier and Koestner $(2008,258)$ have acknowledged that "The need for relatedness has been less studied in past research than the other needs". This is probably because early SDT studies focused on intrinsic motivation, where relatedness support is not needed, and the importance of internalizing and integrating extrinsic motivation was realised only later. What it did mean though, was that the CLT curriculum designers had to create their own notions of what relatedness might mean. We made it up.

First, the module leadership consists of friendly, confident people, experienced as teachers, happy to have open and frank disagreements about what is the right thing to do and why. That is the nature of philosophy and sometimes the nature of shared teaching. There was something rather exciting about being part of a new team and about the membership of that team being unusual (guest lecturers with no assessment obligations, having fun teaching a session outside the normal teaching commitments) which brought a sense of fun and freedom into the lectures. This excitement was a contagion to the students and also for the module leaders who attended each of the weekly lectures; not to check up on content or quality, but to be seen to be sharing the student experience.

Relatedness is about personal connections, so it was important for the CLT tutors to be part of the learning experience with the students. We acknowledge that we too struggle with some of the primary source reading (JS Mill's On Liberty is not easily accessible to a 21 st century reader) and concepts (ethical conundrums are, by definition, hard and puzzling). Relatedness is about a sense of belonging to a community; hence there is a great value added to the learning journey by sharing it in a virtual world with the Harvard students. Relatedness is also about socialisation, reciprocity and respect; so, we made pluralism both a topic area to be studied (Isaiah Berlin), and a practice in class. From the first lecture with the three children and a flute throughout the module, we avoid the possibility of tutor-led indoctrination or the production of canonical answers to problems posed by explicit reliance on pluralism. The end of module questionnaires (n. 72) asked for reports on this aspect of the module and the findings are positive: although $81 \%$ of students were, at times, surprised by the views of other students in tutorials, $91 \%$ of students reported that the tutorials helped them be tolerant in discussion. It is this active tolerance that is testament to the student's sense of community and relatedness. Analysis of these findings against the students who also reported CLT to be interesting reveals that half of the students gained value from the pluralist discourse with others about issues that interest them. Engaging students in what they care about takes this paper full circle and back to Frankfurt, above.

\section{Conclusion}

We are confident that we have drawn on existing research to design a new and structurally unorthodox module which has been shown by the students on the module to have engaged them in numerous ways. This is, therefore, an example of Griffiths' (2004) typology (adapted by Jenkins and Healey (2005)) of teaching-research relationship.

Our research informed our module's learning culture; the environment enabled us to understand students' behaviours, volition and motivation, so we could create ways for the students to internalise extrinsic factors, leading to fully self-determined actions.

\section{REFERENCES}

Amabile, Teresa, William DeJong, and Mark Lepper. 1976. "Effects of externally imposed deadlines on subsequent intrinsic motivation." Journal of Personality and Social Psychology 34: 92-98 
Barnett, Hiliare. 1995. “The Province of Jurisprudence Determined-Again!” Legal Studies 15: $88-127$

Biggs, John. 2003. Teaching for Quality Learning at University, 2nd ed. Maidenhead: Open University Press

Brennan, John, Robert Edmunds, Muir Houston, David Jary, Yann Lebeau, Michael Osborne, and Jack Richardson. 2010. Improving What is Learned at University: An Exploration of the social and organizational diversity of university education. Abingdon: Routledge Brophy, Jere. 1999. "Toward a model of the value aspects of motivation in education: Developing appreciation for particular learning domains and activities." Educational Psychologist 34: 75-85

Brophy, Jere. 2004. Motivating students to learn. Mahwah, New Jersey: Lawrence Erlbaum Byman, Reijo, and Pertti Kansanen. 2008. "Pedagogical Thinking in a Student's Mind: A conceptual clarification on the basis of self-determination and volition theories."

Scandinavian Journal of Educational Research 52(6): 603-621

Cotterrell, Roger. 2000. "Pandora's box: jurisprudence in legal education." International Journal of the Legal Profession. 7: 179

Csikszentmihalyi, Mihaly. 1990. Flow: The Psychology of Optimal Experience. New York:

Harper and Row

Deci, Edward. L. 1971. "Effects of externally mediated rewards on intrinsic motivation." Journal of Personality and Social Psychology 18: 105-115

Deci, Edward. L, and Wayne F. Cascio. 1972. "Changes in intrinsic motivation as a function of negative feedback and threats." Paper presented at the meeting of the Eastern Psychological Association, Boston

Deci, Edward. L, and Richard M. Ryan. 1985. Intrinsic motivation and self-determination in human behavior. New York: Plenum

Deci, Edward. L, Haleh Eghrari, Brian C. Patrick, and Dean R. Leone. 1994. "Facilitating Internalization: The Self-Determination Theory Perspective.” Journal of Personality 62(1): 119-142

Deci, Edward. L, and Richard M. Ryan. 2004. Handbook of Self-Determination Research. University of Rochester Press

Elliott, Andrew, Holly McGregor, and Todd Thrash. 2002. "The Need for Competence.” In Handbook of Self-Determination Research, edited by Edward L. Deci and Richard M. Ryan. University of Rochester Press

Ferris, Graham and Rebecca Huxley-Binns. 2010a. "Are we all going to the same place: pluralism and value driven legal education." Paper presented at the Learning in Law Annual Conference, UK Centre for Legal Education

Ferris, Graham, and Rebecca Huxley-Binns. 2010b. "Escaping the Wasteland: The Multiple Needs for an Explicit Incorporation of Values into the Core Curriculum of Contemporary Legal Education." Journal of the World Universities Forum 3(1): 63-74

Ferris, Graham and Rebecca Huxley-Binns. 2011. "What students care about and why we should care." In Affect and Legal Education, edited by Caroline Maughan and Paul Maharg.

Farnham: Ashgate

Fives, Helenrose, and Patricia Alexander. 2001. "Persuasion as a metaphor for teaching: A case in point." Theory Into Practice, 40, 242-248

Frankfurt, Harry G. 2006. Taking Ourselves Seriously and Getting it Right. Stanford University Press

Gagné, Marylène, and Edward L. Deci. 2005. "Self-determination theory and work motivation" Journal of Organizational Behaviour 26: 331-362

Griffiths, Ron. 2004. "Knowledge production and the research-teaching nexus: the case of the built environment disciplines." Studies in Higher Education 29(6): 709-726

Jenkins, Alan, and Mick Healey. 2005. Institutional strategies to link teaching and research. York: The Higher Education Academy

Koestner, Richard, Richard M. Ryan, Frank Bernieri, and Kathleen Holt. 1984. "Setting limits on children's behavior: The differential effects of controlling versus informational styles on intrinsic motivation and creativity." Journal of Personality 52: 233-248

Kruglanski, Arie, Irith Friedman and Gabrielle Zeevi. 1971. "The Effects of Extrinsic Incentive on Some Qualitative Aspects of Task Performance.” Journal of Personality, 39, 606-617 Lepper, Mark and David Greene. 1975. "Turning Play into Work: Effects of Adult Surveillance and Extrinsic Rewards on Children's Intrinsic Motivation.” Journal of Personality and Social Research, 31, 479-486 
Reeve, Johnmarshall, and Edward L. Deci. 1996. "Elements of the competitive situation that affect intrinsic motivation." Personality and Social Psychology Bulletin 22: 24-33

Ryan, Richard M. and Edward L. Deci. 2000. "Intrinsic and Extrinsic Motivations: Classic Definitions and New Directions" Contemporary Educational Psychology 25: 54-67

Sen, Amartya. 2009. The Idea of Justice. London: Allen Lane

Tan, Seow Hon. 2009. “Teaching Legal Ideals through Jurisprudence.” Law Teacher 43: 14-36

Vallerand, Robert, Luc Pelletier, and Richard Koestner. 2008. "Reflections on Self-determination Theory." Canadian Psychology 49(3): 257-262

Vansteenkiste, Maarten, Willy Lens, and Edward L. Deci. 2006. "Intrinsic versus extrinsic goal contents in self-determination theory: Another look at the quality of academic motivation." Educational Psychologist, 41: 19-31

Zuckerman, Miron, Joseph Porac, Drew Lathin, and Edward L. Deci. 1978. "On the importance of self-determination for intrinsically motivated behavior." Personality and Social

Psychology Bulletin 4: 443-446 